\title{
Non-technical skills of medical students in the course of pediatric emergency simulations are associated with their mindfulness: an observational cohort study
}

\section{Jacek Chmielewski}

Psychotherapy and Psychoeducation

Włodzimierz Łuczyński ( $\nabla$ w.luczynski@wp.pl)

Medical University of Bialystok https://orcid.org/0000-0001-5437-7119

Jakub Dobroch

Uniwersytet Medyczny w Bialymstoku

Grzegorz Cebula

Uniwersytet Jagiellonski w Krakowie Collegium Medicum

Tomasz Bielecki

Uniwersytet Medyczny w Lublinie

Kamil Torres

Uniwersytet Medyczny w Lublinie

Research article

Keywords: medical simulation, pediatrics, medical students, non-technical skills, mindfulness

Posted Date: January 13th, 2020

DOI: https://doi.org/10.21203/rs.2.11230/v2

License: (c) (i) This work is licensed under a Creative Commons Attribution 4.0 International License.

Read Full License 
The authors have withdrawn this preprint from Research Square 